\title{
Environmental Mitigation Measures Critical during Construction and Operational Stages of Road Network in Uyo
}

\author{
J. U. H. Akpabio' ${ }^{1}$ I. D. Edem ${ }^{2 *}$ \\ ${ }^{1}$ Faculty of Environmental Science, Cross River State University of Technology, Calabar, Nigeria \\ ${ }^{2}$ Department of Soil Science and Land Resources Management, University of Uyo, Uyo, Nigeria \\ Email: john_akpabio@yahoo.com, ${ }^{*}$ dennis.edem@gmail.com
}

How to cite this paper: Akpabio, J.U.H. and Edem, I.D. (2017) Environmental Mitigation Measures Critical during Construction and Operational Stages of Road Network in Uyo. Open Access Library Journal, 4: e3561.

https://doi.org/10.4236/oalib.1103561

Received: March 27, 2017

Accepted: April 24, 2017

Published: April 28, 2017

Copyright $\odot 2017$ by authors and Open Access Library Inc.

This work is licensed under the Creative Commons Attribution International License (CC BY 4.0). http://creativecommons.org/licenses/by/4.0/

\begin{abstract}
Since road transport is a dominant necessity for the overall economic development of any nation, the Environmental Impact Assessment (EIA) has been conducted on the soil environmental component to evaluate the effect of the activities of road construction on the project area. The main purpose was to identify any potential significant environmental effects due to the proposed project and proffer mitigation/ameliorative measures. The electrical conductivity value of this soil is non saline. These values are within the tolerance levels for plant growth. The exchangeable cations (bases) ( $\mathrm{Ca}, \mathrm{Mg}, \mathrm{Na}$ and $\mathrm{K}$ ) of the soils of the study area are high and the exchange complex is dominated by $\mathrm{Ca}$ (surface soils, $3.54 \mathrm{cmol} \cdot \mathrm{kg}^{-1}$; subsoils, $3.44 \mathrm{cmol} \cdot \mathrm{kg}^{-1}$ soil), followed by $\mathrm{Mg}$ (surface soils, $1.52 \mathrm{cmol} \cdot \mathrm{kg}^{-1}$; subsoils, $2.55 \mathrm{cmol} \cdot \mathrm{kg}^{-1}$ ), $\mathrm{K}$ (surface soils 0.12 $\mathrm{cmol} \cdot \mathrm{kg}^{-1}$; subsoils, $0.11 \mathrm{cmol} \cdot \mathrm{kg}^{-1}$ ) and $\mathrm{Na}$ (surface soils, $0.06 \mathrm{cmol} \cdot \mathrm{kg}^{-1}$; subsoils, $0.16 \mathrm{cmol} \cdot \mathrm{kg}^{-1}$ ). The percent saturation of basic cations on the sorption sites of the soil micelles which is forced into soil solution where they are assimilated is above $70 \%$. The only notable challenge in this soil area is that potassium availability to plant has been shown to be limited by excessive quantities of exchangeable calcium. The beneficial impact from activities of road construction project is mostly socio-economical. The non-beneficial impacts as it pertains to soil resources include: land uptake and destruction of farmlands, land traffic generation, waste generation, soil pollution and runoff during construction.
\end{abstract}

\section{Subject Areas}

Environmental Sciences

\section{Keywords}

Impacts, Pollution, Environment, Farmland and Soil Properties 


\section{Introduction}

Uyo-Etinan road dualization project is about $19 \mathrm{~km}$ road network from Nung Oku Ikono junction. Soil sampling carried out on ten (10) geo-referenced stations, and these pedon units were assigned as sample identification SS1 - SS10.

\section{Description of Soil Units}

The soil type of the area is Ultisol and is classified as Typic Paleudult [1], having soil units intricately associated together that cannot be demarcated from the other surveys, except in a very detailed soil survey [2]. Even though the geomorphic units have relatively uniform parent materials, the near flatness of the area renders surface recognition of likely boundaries between soil units. No attempt was therefore made to demarcate the soil boundary by taking sufficient soil observations. What was done was to traverse the site and identify as much as possible the major morphological soil units. In this process, a total of forty (bulk and core) samples (top and bottom) were fully sampled and analysed.

\section{Materials and Methods of Study}

In a bid to capture sufficient baseline data of Uyo-Etinan road dualization project, sampling strategies were planned based on certain considerations, which included but not limited to:

1) sampling to obtain baseline data on the specific soil environment of the proposed activity.

2) capturing the potential effects that may be caused by the proposed activity and;

3) sampling strategy that allowed for good coverage of the land resources, which abound in the areas of study.

Field and laboratory protocols for soil studies were carried out in order to obtain information that was adequate and suitable for achieving valuable results. Accordingly, the field and laboratory methods adopted were as described here.

\subsection{Field Methods}

The project is considering road dualization along Uyo-Etinan axis. The location is within the Niger Delta ecosystem in Akwa Ibom State cover between Latitudes $4^{\circ} 59^{\prime} \mathrm{N}$ and $4^{\circ} 50^{\prime} \mathrm{N}$ and Longitudes $7^{\circ} 49^{\prime} \mathrm{E}$ and $7^{\circ} 5^{\prime} \mathrm{E}$. The relief is gently undulating with the general sloping of the land towards the adjacent side at Ikot Oku Ikono section of the road. The soils are derived from coastal plains and are poorly drained due to underground plastic clayey layers with galloping terrain in some locations. The fieldwork plan consisted of soil sampling pattern and sample distribution. The major considerations for these included: 1) baseline data gathering of the specific soil environment of the proposed project; 2) proposed project activities/construction and their spatial locations and; 3) potential project activities/soil environment interfaces (representing potential project impact(s) on the soil environment). A sampling plan involving a combination of 
judgment (based on the above considerations) and systematic samples were adopted. Ten sampling stations were distributed, in a stratified random manner, to cover the proposed site for the road dualization project.

In addition, considerations were given to all the observed soil morphological types. The sampling stations were coded SS1, SS2, SS3, SS4, SS5, SS6, SS7, SS8, SS9, and SS10. Furthermore, another set of core samples were collected for determination of bulk density, porosity, and saturated hydraulic conductivity (Ksat). Soil samples were collected from randomly selected geo-referenced and spatially distributed spots in the study area along the transect lines at two depths (Surface: 0 to $15 \mathrm{~cm}$ and sub-surface: 15 to $30 \mathrm{~cm}$ ) in each sampling point using a Dutch auger (Figure 1) and core samplers. Samples were stored in labelled polyethylene bags for physical and chemical analysis. The samples were qualitatively transported to the laboratory for further processes. All samples were chained custody in the field to facilitate tracking of the samples from the field and the laboratory. On the whole, forty (40) soil samples were collected and transported to the laboratory for analysis.

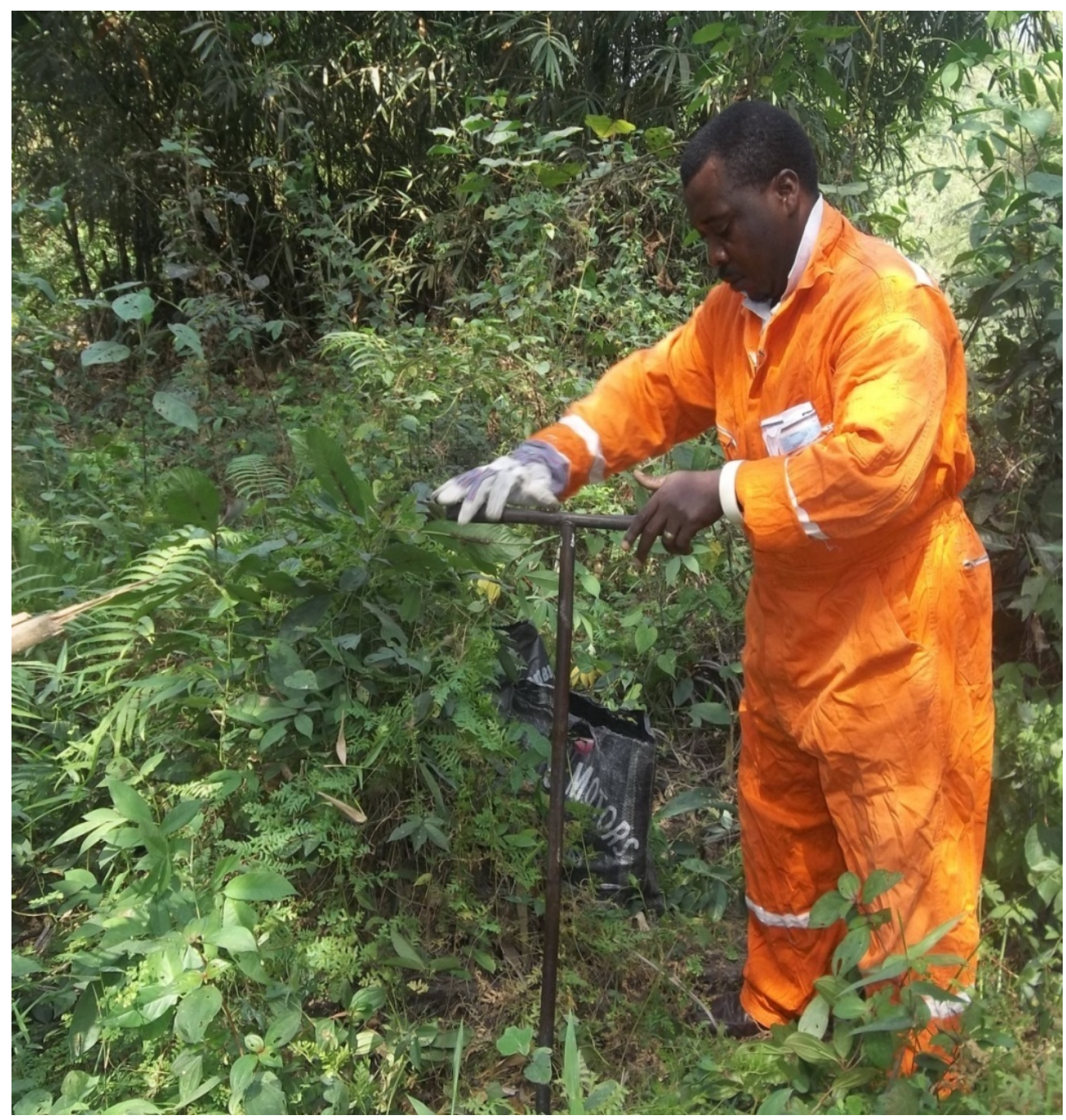

Figure 1. Soil sample collection at one of the stations. 


\subsection{Laboratory Methods}

Analysis was carried out on soil samples for particle size distribution, bulk density, porosity, and Ksat, $\mathrm{pH}$ (soil reaction), electrical conductivity, organic $\mathrm{C}$ contents, total nitrogen, available phosphorus and exchangeable cations $(\mathrm{K}, \mathrm{Ca}$, $\mathrm{Mg}$ and $\mathrm{Na}$ ), effective cation exchange capacity and percent base saturation.

\subsubsection{Particle-Size Analysis}

The Bouyoucos hydrometer method [3], as reported by Gee and Or [4], was used for the soil particles-size analysis. Fifty grammes of air-dry soil, which has been passed through a $2 \mathrm{~mm}$ sieve, was transferred to a stirring cup. To this was added $50 \mathrm{ml}$ of $5.0 \%$ sodium hexametaphosphate (dispersing agent) along with 100 $\mathrm{ml}$ of distilled water and mixed with a stirring rod. After allowing the soil sample to set for 30 minutes, the soil suspension was stirred for 15 minutes with a multimix machine and then transferred from the cup to a glass cylinder. With the hydrometer in the suspension, distilled water was added to the $1000 \mathrm{ml}$ mark. After the hydrometer was removed from the cylinder, the top of the cylinder was covered with the hand and inverted several times until all soil was in suspension.

The cylinder was then placed on flat surface and the time noted. Immediately, soil hydrometer was gently placed into the suspension. The first reading on the hydrometer was taken at 40 seconds after the cylinder was set down. The hydrometer was then removed and the temperature of suspension recorded with a thermometer. After the first hydrometer reading, the suspension was allowed to stand for 2 hours and the second reading taken again, followed by the recording of the suspension temperature. The first reading measures the percentage of silt and clay in suspension, while the second reading indicates the percentage of clay in the suspension. Percent sand was obtained by the difference. Correction was made for temperature and added dispersion agent.

\subsubsection{Bulk Density}

Bulk density was estimated from the methods described by Grossman and Reinsch [5]. To obtain the core samples, each of the cylinders were driven into the soil horizons (of desired depths) by hitting a piece of wood placed on top of the cylinder such that the cylinder did not tilt at any point. Soils around the cylinder's bottom and mouth were trimmed as soon as the cylinders with soil were excavated. The bottom of the cylinder was covered with a piece of cheese cloth that was held in place with a rubber band and then labeled. The soils were carefully transported to the laboratory and thereafter oven dried to a constant weight at $105^{\circ} \mathrm{C}$ and calculated from this model

$$
B d=\frac{M s}{V b}
$$

where,

$$
\begin{aligned}
& B d=\text { bulk density }\left(\mathrm{g} / \mathrm{cm}^{3}\right) \\
& M s=\text { mass of oven dried soil }(\mathrm{g}) \\
& V b=\text { volume of the soil core }\left(\mathrm{cm}^{3}\right)
\end{aligned}
$$




\subsubsection{Porosity}

Porosity $(f)$ is a measure of the volume percentage pore space and is derived from measurement of soil bulk density $(B d)$ and the soil particle density $(D p)$. Since $D p$ represent the ratio of the mass of dry soil to the combined volume of solids and pores, the ratio $B d / D p$ will give the volume fraction of occupied by the solids. The fraction occupied by the pore space is therefore calculated as follows:

$$
f=1-(B d / D p)
$$

where,

$$
\begin{aligned}
& D p=\text { particle density } \\
& B d=\text { bulk density } \\
& f=\text { total porosity. The result is expressed in percentage. }
\end{aligned}
$$

\subsubsection{Saturated Hydraulic Conductivity Ks (Laboratory Measurement)}

\section{Constant Head Permeameter Method}

Saturated hydraulic conductivity (Ks) was determined using the same core used for bulk density by adopting a constant head permeameter method of Klute and Dirksen [6]. This method determines the Ksat of cylindrical, $7 \mathrm{~cm}$ internal diameter by $7 \mathrm{~cm}$ long core of soil. The soil was first wetted to near saturation by capillarity and then water was flowed through the soil at a steady rate under a constant hydraulic head gradient. The quantity of water discharged during this period was measured in a pre-determined time interval, depending on the porous nature of the soil, until a constant quantity of water draining through the soil is attained and the value was used in calculating the Ksat of the soil from this equation:

$$
V=\frac{-K \mathrm{~d} H}{\mathrm{~d} Z}
$$

And

$$
q=V=Q / A t=K \frac{\Delta H}{L}=-K \frac{H A-H B}{L}
$$

But,

$$
\frac{H A-H B}{L}=\frac{h+L}{L}
$$

where, $q=V=$ Flux or Velocity of flow, $H=$ Hydraulic head of water, $H A=h+L$.

$H B=0+0, H=$ Height of water, $\Delta H=H A-H B$ and $h=$ Matric head above the soil column $(\mathrm{cm})$

$$
\frac{\Delta H}{L}=\text { (Driving force) Hydraulic gradient }
$$

Therefore,

$$
\text { Ksat }=\frac{Q L}{A t \Delta H}\left(\mathrm{cmhr}^{-1} \text { or } \mathrm{cmmin}^{-1}\right)
$$


Ksat $=$ Saturated hydraulic conductivity $(\mathrm{cm} / \mathrm{hr}), Q=$ effluent discharged $\left(\mathrm{cm}^{3}\right), A=\Pi r^{2}=$ Cross sectional area of the core cylinder $\left(\mathrm{cm}^{2}\right), \Pi=$ pie (3.14), $r .=$ radius of the core, $L=$ Length of the soil column $(\mathrm{cm}), \Delta H=$ Hydraulic head difference between top and bottom of the cylinder.

\subsubsection{Soil pH}

The soil $\mathrm{pH}$ was determined in water (1:2.5 soil to water ratio), with the aid of a Glass-electrode $\mathrm{pH}$ meter. Twenty grammes of air-dry soil (passed $2 \mathrm{~mm}$ sieve) was weighed into a $50 \mathrm{ml}$ beaker and $20 \mathrm{ml}$ of distilled water added to it. This was allowed to stand for 30 minutes and stirred occasionally with a glass rod. Following this, the electrodes of the $\mathrm{pH}$ meter was inserted into the partly settled suspension and the $\mathrm{pH}$ measured. The $\mathrm{pH}$ meter was calibrated with $\mathrm{pH} 7.0$ and pH 4.0 buffer standards before use.

\subsubsection{Electrical Conductivity}

The soil electrical conductivity was determined with the aid of a conductivity meter. The suspension used for the soil $\mathrm{pH}$ determination was filtered and the electrical conductivity was determined on the filtrate. Calibration was first carried out using standard potassium chloride solution.

\subsubsection{Organic Carbon}

Organic Carbon in soil was determined by the Walkley-Black method as described by Udo et al. [7]. A representative soil sample was ground to pass through $0.5 \mathrm{~mm}$ sieve and $1.0 \mathrm{~g}$ weighed out in duplicate into $250 \mathrm{ml}$ Erlenmeyer flask. Ten milliliters of $1 \mathrm{~N} \mathrm{~K}_{2} \mathrm{Cr}_{2} \mathrm{O}_{7}$ solution was pipetted into each flask and swirled gently to disperse the soil. Twenty milliliters of concentrated $\mathrm{H}_{2} \mathrm{SO}_{4}$ was then added to the suspension and then vigorously for one minute for effective oxidation. One hundred milliliters of distilled water was then added to the contents of the flask after allowing it to stand for 30 minutes. Three drops of ferroin indicator was added to the solution and titrated with $0.5 \mathrm{~N}$ ferrous sulphate solution. The end-point was indicated by a sharp colour change from blue to red in reflected light against a white background. Percent organic carbon in soil was calculated based on titre values.

\subsubsection{Total Nitrogen}

Total nitrogen in soil was determined by the macro Kjeldahl method [8]. A representative soil sample was ground to pass through $0.5 \mathrm{~mm}$ sieve and $5.0 \mathrm{~g}$ weighed out into a dry $500 \mathrm{ml}$ macro-Kjeldahl flask. Twenty millilitres of distilled water was added and then swirled for a few minutes before being allowed to stand for 30 minutes. To this was added one tablet of mercury catalyst and $10 \mathrm{~g}$ of $\mathrm{K}_{2} \mathrm{SO}_{4}$, followed by $30 \mathrm{ml}$ of concentrated $\mathrm{H}_{2} \mathrm{SO}_{4}$. The flask was heated at low heat on the digestion stand until water was removed and frothing ceased. The heat was then increased until digest cleared after which the mixture was boiled for 5 hours. One hundred millilitres of distilled water was added to the digest after it had been allowed to cool and then transferred into a bigger $(750 \mathrm{ml}) \mathrm{ma}-$ cro-Kjeldah flask with the sand particles retained in the original digestion flask. 
The sand residue was then washed with $50 \mathrm{ml}$ of distilled water four times and the aliquot transferred to the $750 \mathrm{ml}$ flask on each occasion. Fifty millilitres of $\mathrm{H}_{3} \mathrm{BO}_{3}$ indicator solution was measured into a $500 \mathrm{ml}$ Erlenmeyer flask and placed under the condenser of the distillation apparatus. The $750 \mathrm{ml} \mathrm{Kjeldahl}$ flask was then attached to the distillation apparatus and $150 \mathrm{ml}$ of $10 \mathrm{~N} \mathrm{NaOH}$ poured through the distillation flask by opening the funnel stopcock. Distillation was then commenced and $150 \mathrm{ml}$ of distillate collected. The ammonium nitrogen in the distillate was determined by titrating with $0.01 \mathrm{~N}$ standard $\mathrm{HC} 1$ with the end-point being indicated by a colour change from green to pink. The percent nitrogen content of the sample was obtained by calculation.

\subsubsection{Available Phosphorous}

Available phosphorous in soil was determined by the Bray No.1 method [9]. One gram of air dried soil, which has been passed through a $2 \mathrm{~mm}$ sieve was weighed into a $15 \mathrm{ml}$ centrifuge tube and $7 \mathrm{ml}$ of the extracting solution of $\mathrm{NH} \mathrm{F}$ and $\mathrm{HC} 1$ added. This was first shaken on a mechanical shaker for one minute before being centrifuged at 2000 revolution per minute for 15 minutes. Two millilitres of the clear supernatant was pipetted into a $20 \mathrm{ml}$ test tube and $5 \mathrm{ml}$ distilled water added followed by $2 \mathrm{ml}$ of ammonium molybdate $\left\{\left(\mathrm{NH}_{4}\right)_{6} \mathrm{MO}_{7} \mathrm{O}_{24}\right\}$ solution. The content was mixed and one millilitre of stannous Chloride $\left\{\mathrm{SnCl}_{2} \cdot 2 \mathrm{H}_{2} \mathrm{O}\right\}$ dilute solution was added and mixed again. After 10 minutes, the percent transmittance of the solution was measured on a spectronic- 20 spectrophotometer at $660 \mathrm{~nm}$ wavelength. The available phosphorous concentration in soil was then calculated with reference to a standard curve of optical density of standard solutions against available phosphorous concentrations.

\subsubsection{Exchangeable Cations}

Exchangeable cations $\mathrm{Ca}, \mathrm{Mg}, \mathrm{K}$ and $\mathrm{Na}$ in soil samples were determined as described by Black [8]. Five grammes of air-dried soil, which has been passed through a $2 \mathrm{~mm}$ sieve was transferred into a centrifuge tube. To this was added $30 \mathrm{ml}$ of $1 \mathrm{~N} \mathrm{NH}_{4} \mathrm{OAC}$ and shaken on a mechanical shaker for 2 hours, then centrifuged at 2000 revolution per minute for 5 minutes. The clear supernatant was decanted into a $100 \mathrm{ml}$ volumetric flask and another $30 \mathrm{ml}$ of $\mathrm{NH}_{4} \mathrm{OAC}$ solution was added to the residue, shaken for 30 minutes and centrifuged. The supernatant was transferred into the same volumetric flask and the step repeated again before the flask was made up to mark with the $\mathrm{NH}_{4} \mathrm{OAC}$ solution. Potassium, Sodium and Calcium were determined from the supernatant with the aid of a flame photometer, while magnesium $(\mathrm{Mg})$ was determined by atomic absorption spectrophotometry. Consideration was taken of the dilution factor in concentration calculations.

\subsubsection{Effective Cation Exchange Capacity and Base Saturation}

Effective cation exchange capacity (ECEC) was obtained by addition of the values of exchangeable bases and exchangeable acidity. Base saturation was expressed as the fraction of the negative binding sites occupied by exchangeable cations. It was calculated by summing together the levels of $\mathrm{Ca}, \mathrm{Mg}, \mathrm{K}$, and $\mathrm{Na}$ 
found in the soil, then expressing this sum as a percentage of the ECEC value as follows:

$$
B S=\frac{100(\mathrm{Ca}+\mathrm{Mg}+\mathrm{K}+\mathrm{Na})}{\mathrm{ECEC}}
$$

where $B S$ represents base saturation (\%).

\section{Results and Discussion}

\subsection{Particle Size Distribution and Morphological Characteristics}

The particle size distribution is a fundamental index of soil physical properties. Knowledge of this property allows prediction of many other soil properties [10]. In general, the soils of the humid tropics are subject to intense rain storms which often cause clay eluviations with resultant tendency toward coarse texture in the surface horizons. The physico-chemistry of soil samples from field (Table 1 and Table 2) showed that the soils are dominated by sand and loamy sand. The mean values for the particle size distribution of surface soils $(0-15 \mathrm{~cm})$ are $88.48 \%, 10.98 \%$ and $4.70 \%$ for sand, silt and clay, respectively. Sub soil (15- 30 $\mathrm{cm}$ ) results indicated that mean percent sand, silt and clay are $89.91 \%, 2.31 \%$ and $7.78 \%$ respectively. Normally, soil fertility increases with clay content because of the large surface area. Thus the production capacity of these soils is low.

The bulk density varied from $1.13 \mathrm{~g} \cdot \mathrm{cm}^{-3}$ (SS8) to $1.42 \mathrm{~g} \cdot \mathrm{cm}^{-3}$ (SS10) on the surface soils and from $0.95 \mathrm{~g} \cdot \mathrm{cm}^{-3}$ (SS2) to $1.33 \mathrm{~g} \cdot \mathrm{cm}^{-3}$ (SS8). The activity on the road side has not influenced the bulk density negatively as would have expected.

Table 1. Physical properties of surface soil along Uyo-Abak-Etinan road.

\begin{tabular}{|c|c|c|c|c|c|c|}
\hline Sample ID & $\begin{array}{c}\text { Bulk density } \\
\mathrm{g} \cdot \mathrm{cm}^{-3}\end{array}$ & $\begin{array}{c}\text { Porosity } \\
\%\end{array}$ & Sand & $\begin{array}{l}\text { Silt } \\
\%\end{array}$ & Clay & Texture \\
\hline SS1 & 1.15 & 56.6 & 94.6 & 42 & 1.2 & S \\
\hline SS2 & 1.34 & 49.43 & 85 & 10.2 & 4.8 & LS \\
\hline SS3 & 1.22 & 53.96 & 85.4 & 10.2 & 6.8 & LS \\
\hline SS4 & 1.26 & 52.45 & 91.8 & 4.2 & 0 & S \\
\hline SS5 & 1.2 & 54.72 & 95 & 4.2 & 0.8 & S \\
\hline SS6 & 1.28 & 51.7 & 85 & 4.2 & 10.8 & LS \\
\hline SS7 & 1.31 & 50.57 & 85 & 12.2 & 8.8 & LS \\
\hline SS8 & 1.13 & 57.36 & 87 & 8.2 & 4.2 & LS \\
\hline SS9 & 1.21 & 54.34 & 89 & 6.2 & 4.8 & LS \\
\hline SS10 & 1.42 & 46.42 & 87 & 8.2 & 4.8 & LS \\
\hline Mean & 1.25 & 52.76 & 88.48 & 10.98 & 4.70 & \\
\hline minimum & 1.13 & 46.42 & 85 & 4.2 & 0 & \\
\hline maximum & 1.42 & 57.36 & 95 & 42 & 10.8 & \\
\hline skewness & 0.4992 & -0.4982 & 0.849 & 2.798 & 0.330 & \\
\hline kurtosis & -0.0920 & -0.0947 & -0.919 & 8.325 & -0.484 & \\
\hline CV\% & 7.09 & 6.35 & 4.48 & 102.55 & 73.79 & \\
\hline
\end{tabular}

Where $\mathrm{S}=$ sandy, $\mathrm{LS}=$ loamy sand, $\mathrm{CV}=$ coefficient of variation. 
Table 2. Physical properties of sub-surface soil along Uyo-Abak-Etinan road.

\begin{tabular}{|c|c|c|c|c|c|c|}
\hline Sample ID & $\begin{array}{l}\text { Bulk density } \\
\mathrm{g} \cdot \mathrm{cm}^{-3}\end{array}$ & $\begin{array}{c}\text { Porosity } \\
\%\end{array}$ & Sand & $\begin{array}{l}\text { Silt } \\
\%\end{array}$ & Clay & Texture \\
\hline SS1 & 1.05 & 60.38 & 90.7 & 1.5 & 7.8 & Sand \\
\hline SS2 & 0.95 & 64.15 & 88.7 & 2.5 & 8.8 & Sand \\
\hline SS3 & 1.16 & 56.23 & 85.7 & 4.5 & 9.8 & Sand \\
\hline SS4 & 1.04 & 60.75 & 85.7 & 3.5 & 10.8 & Sand \\
\hline SS5 & 1.22 & 53.96 & 86.7 & 3.5 & 9.8 & Sand \\
\hline SS6 & 1.18 & 55.47 & 90.7 & 1.7 & 7.6 & Sand \\
\hline SS7 & 1.08 & 59.25 & 93.1 & 1.2 & 5.7 & Sand \\
\hline SS8 & 1.33 & 49.81 & 91.7 & 2.1 & 6.2 & Sand \\
\hline SS9 & 1.14 & 56.98 & 92.7 & 1.2 & 6.1 & Sand \\
\hline SS10 & 1.04 & 60.75 & 93.4 & 1.4 & 5.2 & Sand \\
\hline Mean & 1.12 & 57.77 & 89.91 & 2.31 & 7.78 & \\
\hline minimum & 0.95 & 49.81 & 85.7 & 1.2 & 5.2 & \\
\hline maximum & 1.33 & 64.15 & 93.4 & 4.5 & 10.8 & \\
\hline skewness & 0.4792 & -0.4800 & -0.409 & 0.865 & 0.188 & \\
\hline kurtosis & 0.2498 & 0.2507 & -1.539 & -0.514 & -1.472 & \\
\hline CV\% & 9.78 & 7.15 & 3.35 & 50.05 & 25.22 & \\
\hline
\end{tabular}

The soil volume consisted of pore space, and the pore space would be half-filled with water and half-filled with air [9]. Actually the total porosity varies slightly with soils at different sampling stations. The locations mostly affected were stations; SS1, SS2, SS4 and SS10, where the average porosity was between $14 \%$ and $26 \%$ higher than optimum.

This implies that runoff and erosion losses of soil and nutrients are occasioned by excessive and tortuous pore spaces when surface water is restricted from moving through the soil. Plant, tree and forest ecosystem are particularly sensitive to increases in porosity. The anthropogenic activity of the area generally disturbed configuration of the pore spaces especially in the subsurface soil. This level of pore distortion at these locations may result in yield reductions, deplete respiration by plant root especially under wet condition and alter many soil reactions, in turn many soil properties.

Furthermore, the readiness of the soil to allow fluid to pass through it accounts for its permeability [11]. Figure 2 showed the saturated hydraulic conductivity (Ksat) distribution of soils at different locations along Uyo-Etinan Road. The Ksat rate of this area is most responsive to conditions near the soil surface and changes drastically with depth. According to Sarrantonio et al. [12], Ksat is rapid into large continuous pores at the soil surface and decreases as the size of these pores is reduced. Hillel [13] reported that the coarser size fractions acted as an energy source for saturated hydraulic conductivity Ksat. The trend of accumulative saturated hydraulic conductivity of soils is continous higher on the surface soil compared to the subsurface. The soils at locations 3, 4, and 5 exhibited the highest non-equal uniformity permeability and the least impermeable 


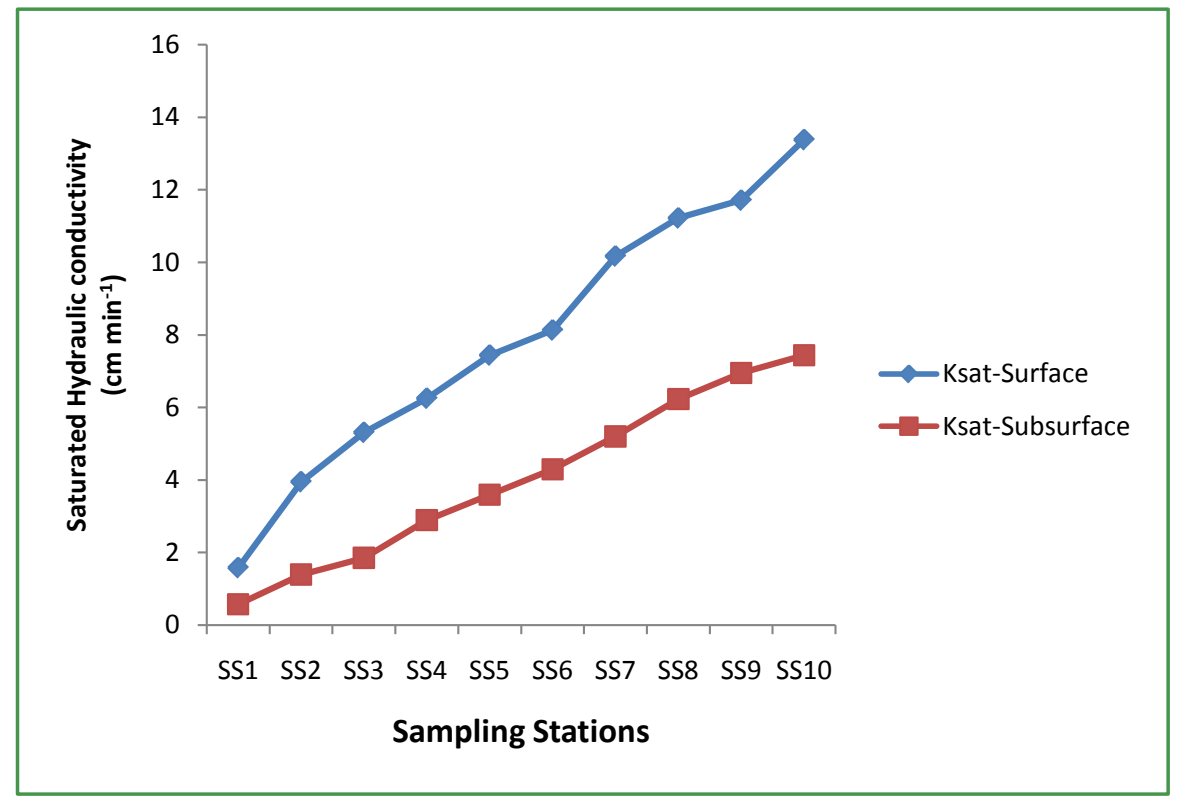

Figure 2. Showing the trend of cumulative saturated hydraulic conductive of soils along Uyo-Etinan Road.

permeability classes. Edem et al. [14] found that a continous flux of Ksat on the surface soil without a corresponding flow in the subsurface during rainstorm will lead to immediate over-land flow in less than 30 minutes of storm due to proportion of silt to clay ratio.

\subsection{Soil pH (Reaction)}

Soil reaction which is given in terms of $\mathrm{pH}$ value is a measure of the free hydrogen ion $\left(\mathrm{H}^{+}\right)$concentration of soil solution. The value of the free $\mathrm{H}^{+}$concentration in a soil influences the availability of nutrient elements and biochemical reactions in the soil [15]. In strongly acidic soils for instance basic cation uptake by plant roots is inhibited [16]. Beneficial soil micro organisms are affected by soil reaction [17]. The $\mathrm{pH}$ of the soil of the Uyo-Etinan dualization road (Table 3 and Table 4) ranged from strongly acidic to slightly acidic. It ranged from a very strong acidic value of 4.7 (sample stations 8 ) to strongly acidic value of 5.3 (sample station 2) at the surface level and from 4.2 (sample station 8) to 5.7 (sample station 3) at the sub surface level. Soil pH is often considered in terms of the soil capability and suitability to support plant growth. The $\mathrm{pH}$ of 4.8 is set as the lower limit for optimum growth of plants, and conversely the $\mathrm{pH}$ of 9.5 is regarded as the extreme upper limit of alkalinity at which plants can still grow [18]. Even though the soil $\mathrm{pH}$ value of sample stations 7 and 8 (subsoil) is short of this limit, the coefficient of variation among sampling stations is low, thus the soil $\mathrm{pH}$ of Uyo-Etinan dualization road can support plant growth.

\subsection{Electrical Conductivity}

The electrical conductivity of a soil indicates the total ionic strength (anions and cations) of such a soil. Low total ionic strength in a soil indicates low dissolved 
Table 3. Chemical properties of surface soil along Uyo-Etinan road.

\begin{tabular}{ccccccccccccccc}
\hline Sample ID & $\mathrm{pH}$ & $\mathrm{EC}$ & Organic C & Total N & Av P & Ca & Mg & Na & K & EA & ECEC & BS \\
\hline SS1 & 4.9 & 0.087 & 3.06 & 0.08 & 43.1 & 3.2 & 1.6 & 0.06 & 0.12 & 1.91 & 6.89 & 72.28 \\
SS2 & 5.3 & 0.065 & 5.34 & 0.13 & 43.5 & 4.11 & 1.8 & 0.05 & 0.11 & 2.20 & 8.27 & 73.40 \\
SS3 & 4.9 & 0.062 & 2.92 & 0.07 & 47.2 & 3.6 & 1.4 & 0.05 & 0.1 & 2.10 & 7.25 & 71.03 \\
SS4 & 5.2 & 0.054 & 2.96 & 0.07 & 38.3 & 6.01 & 1.5 & 0.07 & 0.13 & 1.90 & 6.61 & 71.26 \\
SS5 & 5.1 & 0.046 & 2.55 & 0.06 & 49.5 & 2.96 & 1.3 & 0.04 & 0.09 & 1.89 & 6.28 & 69.90 \\
SS6 & 4.8 & 0.026 & 1.43 & 0.04 & 29.3 & 2.66 & 1.2 & 0.04 & 0.1 & 1.68 & 5.62 & 70.11 \\
SS7 & 4.8 & 0.032 & 1.12 & 0.03 & 29.5 & 2.8 & 1.4 & 0.05 & 0.12 & 1.60 & 5.97 & 73.20 \\
SS8 & 4.7 & 0.027 & 2.14 & 0.05 & 29.6 & 3.2 & 1.6 & 0.06 & 0.11 & 2.10 & 7.07 & 70.30 \\
SS9 & 4.8 & 0.038 & 1.53 & 0.04 & 35.4 & 3 & 1.6 & 0.07 & 0.13 & 2.20 & 6.99 & 68.53 \\
SS10 & 5.0 & 0.049 & 3.98 & 0.1 & 37.4 & 3.9 & 1.8 & 0.06 & 0.15 & 1.76 & 7.67 & 77.05 \\
Mean & 5.0 & 0.05 & 2.70 & 0.07 & 38.28 & 3.54 & 1.52 & 0.06 & 0.12 & 1.93 & 6.86 & 71.71 \\
Minimum & 4.7 & 0.026 & 1.12 & 0.03 & 29.3 & 2.66 & 1.2 & 0.04 & 0.09 & 1.6 & 5.62 & 68.53 \\
Maximum & 5.3 & 0.087 & 5.34 & 0.13 & 49.5 & 6.01 & 1.8 & 0.07 & 0.15 & 2.2 & 8.27 & 77.05 \\
Skewness & 0.666 & 0.70810 & 0.8455 & 0.9382 & 0.100 & 1.9852 & 0.025 & -0.0000 & 0.4638 & -0.1773 & 0.1561 & 1.1413 \\
Kurtosis & -0.647 & 0.21474 & 0.7501 & 0.6574 & -1.371 & 4.5125 & 0.760 & -1.0321 & 0.0539 & -1.2324 & 0.0841 & 1.7622 \\
CV\% & 3.96 & 39.55 & 47.23 & 45.62 & 19.43 & 27.81 & 13.08 & 19.64 & 15.31 & 10.99 & 11.48 & 3.37 \\
\hline
\end{tabular}

Table 4. Chemical properties of sub-surface soil along Uyo-Etinan road.

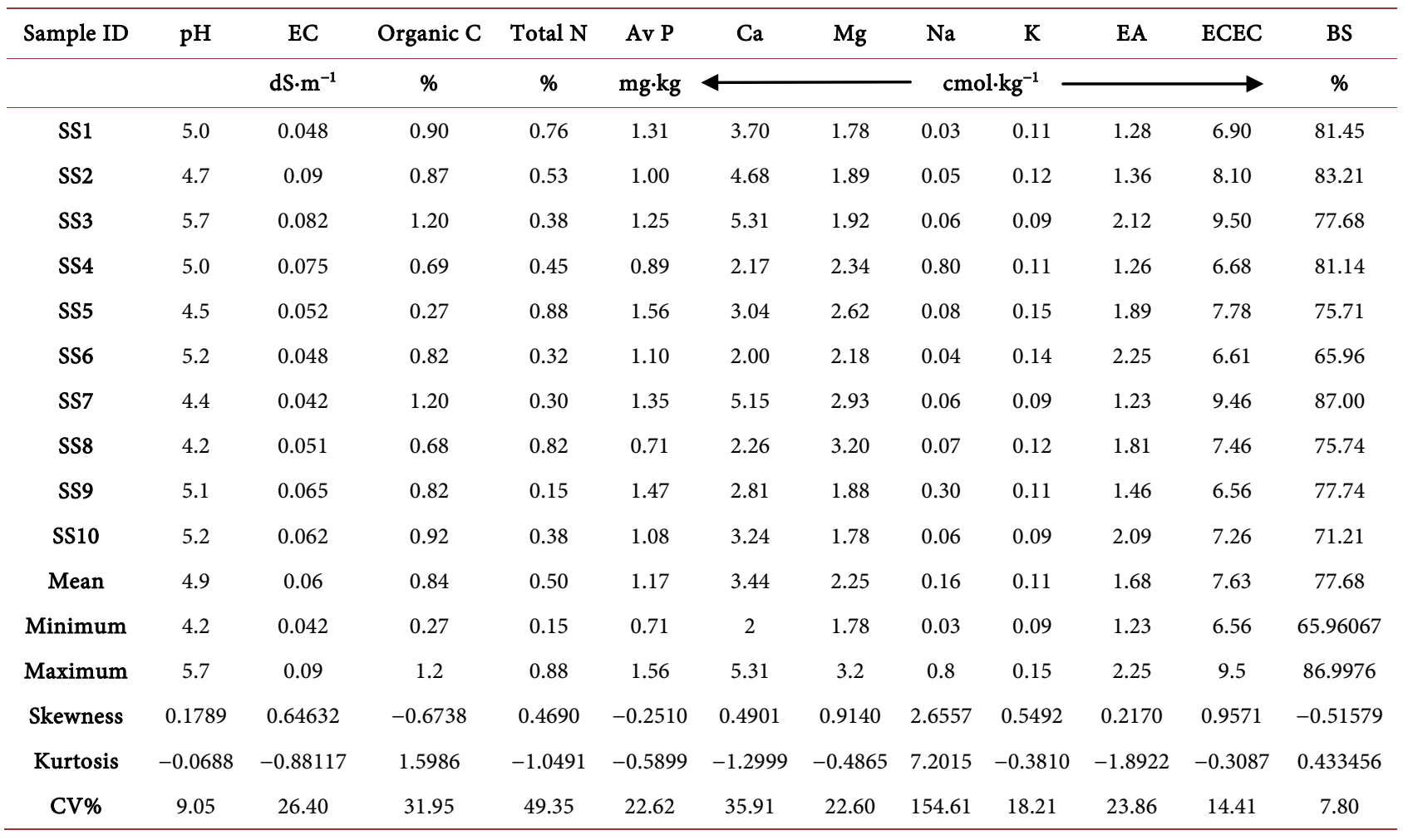

salt contents and vice versa. Consequently Electrical conductivity increases with higher amount of soluble salts. Electrical conductivity values of soils of 
Uyo-Etinan dualization road ranged from $0.026 \mathrm{dS} \cdot \mathrm{m}^{-1}$ (sample station 6) to $0.087 \mathrm{dS} \cdot \mathrm{m}^{-1}$ (sample station 1) at the surface level with a mean value of 0.05 $\mathrm{dS} \cdot \mathrm{m}^{-1}$ and from $0.042 \mathrm{dS} \cdot \mathrm{m}^{-1}$ (sample station 7) to $0.09 \mathrm{dS} \cdot \mathrm{m}^{-1}$ (sample station 2 ) at the sub surface level. The electrical conductivity value of this soil is non saline. These values are within the tolerance levels for plant growth. Electrical conductivity tolerance levels for plants growing on soils have been set at 4000 $\mu \mathrm{s} / \mathrm{cm}\left(4 \mathrm{dS} \cdot \mathrm{m}^{-1}\right)$ in the saturated soil extract [19].

\subsection{Total Organic Carbon (TOC)}

Soil organic C usually mixed up with fine clay particles to form soil colloids. It's an important soil fraction due to its binding properties that enhanced most physical and chemical activities in the soil [20]. Thus, there is increased contact with other colloids and with soil solution. The TOC varies significantly $(\mathrm{p}<$ 0.001). Pair-wise mean difference showed significantly higher TOC on the surface soil compared to the subsurface. About $80 \%$ of stations sampled had TOC less than $1 \%$ in the subsurface soil. This result implies that there is a strong friction and cohesion bonds between particles and soil water, and it is imperative that soil at the $0-15 \mathrm{~cm}$ depth holds aggregates together better than a sandy soil subsoil when wet. Total organic $\mathrm{C}$ reduced downward by $68.8 \%$ from the surface soil. It ranged from 1.12 (Station 7) to $5.34 \%$ (station 2) averaged $2.70 \%$ at the surface level and from 0.270 (Station 5) to $1.20 \%$ (Stations $3 \& 7$ ), with a mean value of $0.84 \%$ at the sub surface level. The ground biomass on the surface soil contributed more than $37 \%$ to the TOC compared to the subsurface soils. For an overall view, this site is low in organic $\mathrm{C}$, and this could be attributed to high $\mathrm{C}$ sequestration associated with poor soil management that decreases TOC content of the soil.

\subsection{Total Nitrogen}

Total nitrogen content of the surface soil in the study area is low $(<0.10 \%)$. The mean values are $0.07 \%$ and high on the subsurface with a mean value of $0.50 \%$, while range of values are from 0.03 (Station 7) to $0.13 \%$ (station 2) for surface soils and 0.15 (Station 9) to $0.88 \%$ (Station 5) for subsoils. The high total nitrogen contents of the subsoils are attributable to the high organic matter contents at this depth. The amount of $\mathrm{N}$ in the soil is an indication of how suitable the soils environmental conditions are, and the content in this study site could be classified as very low to high concentration.

\subsection{Phosphorus}

Phosphorus is one of the nutrients that is very essential for plant growth. However not all the total phosphorus in the soil is available for plant uptake [21]. This is because phosphorus occurs in soil matrix either in the occluded or solution form. Only the solution form of phosphorus is available for plant uptake. Most of the phosphorus in tropical soils that are available for plant uptake is induced by microbial activities in the soil. Thus phosphorus availability is also af- 
fected by soil environmental factors that affect microbial activities. Available phosphorus content of soils from the study area is high on the surface $(>8.00$ $\mathrm{mg} / \mathrm{kg}$ ) The Phosphorus contents ranged from $29.3 \mathrm{mg} / \mathrm{kg}$ (Station 6) to 49.5 $\mathrm{mg} / \mathrm{kg}$ (sample station 5) at the surface soil level and from $0.71 \mathrm{mg} / \mathrm{kg}$ (sample station 8) to $1.56 \mathrm{mg} / \mathrm{kg}$ (sample station 5) at the subsurface soil level. The phosphorus content decreased down the depth and is considered low $(<8 \mathrm{mg} / \mathrm{kg})$ at the subsurface level.

\subsection{The Exchangeable Cations}

Cation exchange is important reaction in soil fertility; in correcting soil acidity and basicity, in altering soil physical properties and as a mechanism in purifying percolating waters [22]. The exchangeable cations (bases) ( $\mathrm{Ca}, \mathrm{Mg}, \mathrm{Na}$ and $\mathrm{K}$ ) of the soils of the study area are high and the exchange complex is dominated by Ca (surface soils: $3.54 \mathrm{cmol} \cdot \mathrm{kg}^{-1}$; subsoils: $3.44 \mathrm{cmol} \cdot \mathrm{kg}^{-1}$ soil), followed by $\mathrm{Mg}$ (surface soils: $1.52 \mathrm{cmol} \cdot \mathrm{kg}^{-1}$; subsoils: $2.55 \mathrm{cmol} \cdot \mathrm{kg}^{-1}$ ), $\mathrm{K}$ (surface soils: 0.12 $\mathrm{cmol} \cdot \mathrm{kg}^{-1}$; subsoils: $0.11 \mathrm{cmol} \cdot \mathrm{kg}^{-1}$ ) and $\mathrm{Na}$ (surface soils: $0.06 \mathrm{cmol} \cdot \mathrm{kg}^{-1}$; subsoils: $\left.0.16 \mathrm{cmol} \cdot \mathrm{kg}^{-1}\right)$.

However, any flowing water in this soil will lose its soluble cations ( $\mathrm{Ca}$ and $\mathrm{Mg}$ ) to the exchange site. This reduces the leaching loss and their mobility in the soil. The disadvantage is that, should any potential pollutants, such a $\mathrm{Pb}$ or $\mathrm{Cd}$ is disposed to this soil, instead of leaching easily, the will be adsorbed to the cation exchanged sites. Therefore, deposition of materials with heavy metal contents should be properly guided.

At the same time, higher $\mathrm{Ca}$ and $\mathrm{Mg}$ availability in the soil solution facilitate the association between clay and sand $(r=0.841$ and -0.767 surface and subsurface respectively), which is supported by the high correlation observed between TOC and the K (-0.820), Ca and ECEC (0.867) contents on the surface soils. The formation of cation chemical bonds between TOC and ECEC is a common mechanism of SOM stabilization, and Ca is very important in the establishment of these bonds [23]. Hence, these chemical bonds between the TOC and the minerals of these soil fractions constitute a chemical protection of the organic compounds, impeding their decomposition [20].

\section{Impacts and Mitigation}

The beneficial impact from the activities of road construction project is mostly socio-economical. More job opportunities will improve income and probable introduction of indigenes with new skills and prospective. The non beneficial impacts as it pertains to soil resources include:

\section{* Destruction of farmlands}

Ordinarily, a major impact of road construction on soil resources will be occasioned by land-uptake and destruction of farmlands along the $19 \mathrm{~km}$ stretch. Of necessity, some farms will have to be destroyed while grading the road. According to National Road Authority (NRA) [24], the entire civil construction activities will involve cut and fill process generally involving the stages of: 
Top soil removal

Ditching involving subsoil removal

Backfilling

Soil management and reinstatement

The company should pay adequate compensation for the land take and farmlands in line the company's procedure and Federal Government Land Use decree. They should avoid excessive land take and minimize bush clearing during site survey.

\section{Land traffic generation}

There will be increased land logistics supplies during the land clearing and construction activities, since materials, equipments and workers will be moved to and from the site as operations demand. The land traffic shall minimized by embarking only on approved journeys in line with civil engineering management guidelines to avoid increased road and work place accidents.

\section{* Waste generation}

Any developmental project involving bush clearing and excavation in any environment such as road construction area between Uyo and Etinan is bound to encounter a waste management problem which needs to be handling in compliance with Civil Engineering regulation.

The construction company should enforce proper waste management practices and good in-house sanitary practices for base camp workforce.

\section{Soil pollution}

On site preparation and construction activities will involving dry plants made up of Bulldozers, Front end loaders, Trucks and small personnel carriers like motor cars will likely spills engine oil, diesel, and petrol during the project execution and this will increase the total hydrocarbon content of the soils.

Use equipment with acceptable exhaust gases which conform to national standards and civil engineering specifications. Also, reduce to the barest minimum contamination of soil, water and vegetation, with liquid fuel and lubricants from machines and vehicles during refueling.

\section{* Runoff control during construction}

Major construction or civil works should be during dry season or silt curtains should be provided to control the suspended particles in the runoff during wet season. Time frame between clearing, trenching, excavating and backfilling should be reduced.

\section{Conclusions and Recommendation}

In conclusion, the dynamics of soil properties including the prevailing environmental conditions and anthropogenic impacts, account for variations in the studied areas. This study provides valuable insight on the spatial and temporal patterns of soil properties along Uyo-Etinan road. The test results of base saturation and effective exchanged cations confirmed the significant availability of nutrients to both plants and micro organisms. The percent saturation of basic cations on the sorption sites of the soil micelles which is forced into soil solution 
where they are assimilated is above $70 \%$. The only notable nutrient challenge in this soil area is that potassium availability to plant has been shown to be limited by excessive quantities of exchangeable calcium.

The significance of the impacts has been duly assessed through standard field and laboratory methodologies, predictive modeling as well as desk reviews. The EIA has demonstrated that the overall impacts associated with soils along Uyo-Etinan road dualization project can be managed within reasonable and acceptable limits by applying all identified mitigation measures contained in this report. In consideration of the above, all major environmental issues related to soil resources would have been properly mitigated.

\section{References}

[1] USDA (2006) 2007 Farm Bill Theme Paper-Energy and Agriculture. United States Department of Agriculture, Washington DC.

[2] Edem, I.D. and Udo-Inyang, U.C. (2012) Relationship of Landscape Positions with Soil Properties on Maize (Zea mays L.) Yield in Ultisol. Basic Research Journal of Agricultural Science and Review, 1, 69-76.

[3] Bouyoucos, G.H. (1951) A Recalibration of the Hydrometer Method for Making Mechanical Analysis of Soils. Agronomy Journals, 43, 434-438. https://doi.org/10.2134/agronj1951.00021962004300090005x

[4] Gee, G.W. and Or, D. (2002) Particle Size Analysis. In: Dane, J.H. and Topp, G.C., Eds., Methods of Soil Analysis. Part 4, Physical Methods, SSSA, Incorporated, Madison, 255-294.

[5] Grossman, R.B. and Reinsch, T.G. (2002) Bulk Density and Linear Extensibility: Core Method. In: Dane, J.H. and Topp, G.C., Eds., Methods of Soil Analysis. Part 4, Physical Methods, SSSA, Incorporated, Madison, 208-228.

[6] Klute, A. and Dirksen, C. (1986) Methods of Soil Analysis No. 9 Part 21, Physical and Mineralogical Analysis. American Society of Agronomy, Monograph. Madison Winsc.

[7] Udo, E.J., Ibia, T.O., Ogunwale, A., Ano, O. and Esu, I.E. (2009) Manual of Soil, Plant and Water Analysis Lagos. Sibon Books Limited, Festac Town, Amuwo-Odofin, Lagos.

[8] Blake, G.R. (1965) Physical and Mineralogical Properties, Including statistics of Measurement and Sampling. In: Black, C.A., Ed., Methods of Soil Analysis, Part 1, ASA-SSSA, Agronomy Monograph, Vol. 9, 374-390.

[9] Klute, A. (1965) Physical and Mineralogical Properties, Including Statistics of Measurement and Sampling. In: Black, C.A., Ed., Methods of Soil Analysis, Part 1, ASA-SSSA, Agronomy Monograph, Vol. 9, 273-278.

[10] Arshad, M.A., Lowery, B. and Grossman. B. (1996) Physical Tests for Monitoring Soil Quality. In: Doran, J.W. and Jones, A.J., Eds., Methods for Assessing Soil Quality, Soil Science Society of America Special Publication 49, SSSA, Madison, WI, 123-142.

[11] Keeney, D.R., and Nelson, D.W. (2007) Chemical and Microbiological Property ASA-SSSA. In: Page, A.L., Ed., Methods of Soil Analysis, Part 2 (Second Edition). Agronomy Monograph, Vol. 9, 643-698.

[12] Sarrantonio, M., Doran, J.W., Liebig, M.A. and Halvorson, J.J. (1996) On-Farm Assessment of Soil Quality and Health. In: Doran, J.W. and Jones, A.J., Eds., Methods for Assessing Soil Quality, SSSA Special Publication 49, Soil Science Society of 
America, Inc., Madison, Wisconsin, 83-106.

[13] Hillel, D. (1982) Introduction to Soil Physics. Academic Press, San Diego.

[14] Edem, I.D., Udo-Inyang, U.C. and Nkereuwem, M.E. (2015) Runoff and Erosion from Phosphorus Enriched Soil and Eutrophication of Receiving Water in the Downstream. International J Ext Res., 4, 55-59.

[15] Doran, J.W. and Jones, A.J. (1996) Methods for Assessing Soil Quality. SSSA Publication No. 49, Soil Science Society of America, Madison, WI.

[16] Thomas, G.W. (1996) Soil pH and Soil Acidity. In: Sparks, D.L., Ed., Methods of Soil Analysis. Part 3-Chemical Methods, Book Series No. 5, SSSA and ASA, Madison, WI, 475-489.

[17] McLean, E.O. (1982) Chemical and Microbiological Properties. In: Page, A.L., Ed., Methods of Soil Analysis, Part 2 (Second Edition), ASA-SSSA, Agronomy Monograph, Vol. 9, 199-224.

[18] Treoh, F.R. and Thompson, L.M. (1993) Soils and Soil Fertility. 5th Edition, New Oxford University Press, Oxford.

[19] Soil Survey Staff (1993) Soil Survey Manual. United States Department of Agriculture, Washington DC.

[20] Lowery, B., Arshad, M.A., Lal, R. and Hickey, W.J. (1996) Soil Water Parameters and Soil Quality. In: Doran, J.W. and Jones, A.J., Eds., Methods for Assessing Soil Quality, Soil Science Society of America Special Publications 49, SSSA, Madison, 143-157.

[21] Doran, J.W., Coleman, D.C., Bezdicek, D.F. and Stewart, B.A., Eds. (1994) Defining Soil Quality for a Sustainable Environment. SSSA Publication No. 35, Madison, WI.

[22] Soares, D.L., Mausbach, M.J., Doran, J.W., Cline, R.G., Harris, R.F. and Schuman, G.E. (2005) Soil Quality: A Concept, Definition, and Framework for Evaluation. Soil Science Society of America Journal, 61, 4-10.

[23] Evanylo, G.K. and Alley, M.M. (1997) Preside Dress Soil Nitrogen Test for Corn in Virginia. Communications in Soil Science and Plant Analysis, 28, 1285-1301. https://doi.org/10.1080/00103629709369874

[24] National Road Authority (NRA) (2008) Environmental Impact Assessment of National Road Scheme-A Practical Guide. Revision 1, 20 November, 2008.

Submit or recommend next manuscript to OALib Journal and we will provide best service for you:

- Publication frequency: Monthly

- 9 subject areas of science, technology and medicine

- Fair and rigorous peer-review system

- Fast publication process

- Article promotion in various social networking sites (LinkedIn, Facebook, Twitter, etc.)

- Maximum dissemination of your research work

Submit Your Paper Online: Click Here to Submit

Or Contact service@oalib.com 